\title{
Alien Abductions: A Case of Sleep Paralysis
}

\author{
Javed Ather Siddiqui ${ }^{1,2 *}$, Shazia Farheen Qureshi ${ }^{1,3}$, Abdul Khaliq Al Ghamdi ${ }^{4,5}$ \\ ${ }^{1}$ Department of Psychiatry, Mental Health Hospital, Taif, Saudi Arabia \\ 'Seth GS Medical College and KEM Hospital, Mumbai (INDIA) \\ ${ }^{3}$ Government Medical College, Aurangabad (Maharashtra) INDIA \\ ${ }^{4}$ Consultant Psychiatrist and Head of Psychiatry Department, Mental Health Hospital, Taif, Saudi Arabia \\ ${ }^{5}$ Arab board of Psychiatry, Saudi Arabia
}

\begin{abstract}
Sleep paralysis (SP) is a benign, transient episode of immobility lasting a few seconds to a few minutes that can occur while falling asleep or on awakening. It is a condition of unknown etiology. During the episode, all the skeletal muscles are virtually 'paralyzed', resulting in an inability to move or speak but individual remains conscious. Because it occurs in a clear sensorium, the individual is able to describe the experience vividly. It is associated with extreme anxiety, phobia, and nervousness, restless and, sometime, hallucinations.

We present a case of 35 year old male personal driver, who had recurrent episode of sleep paralysis, we must rule out physical, psychological or social suffering and the subject must be examined by sleep clinicians or psychiatrist. "Supernatural" experiences associated to SP have been interpreted as pathological. We must enrich the knowledge about these experiences of SP and their psychological and cultural aspects. SP may be misdiagnosed as being due to depression and psychosis (e.g. schizophrenia) and alternatively depending on how they construe these experiences.

Keywords: Sleep paralysis, Alien abductions, Sleep disorder, Cultural significances Sleep paralysis, Alien abductions, Sleep disorder, Cultural significances
\end{abstract}

\section{INTRODUCTION}

Sleep paralysis (SP) is a dissociative state in which an individual, upon going to sleep or waking up, is unable to move (Mahowald et al., 2011). SP is accompanied by frightening, and often fantastic, hallucinations and delusions (Dahlitz \& Parkes, 1993), thus different societies interpreted it under a supernatural or metaphysical perspective (Hinton et al., 2005). During the episode, all the skeletal muscles are virtually 'paralyzed', resulting in an inability to move or speak. Because it occurs in a clear sensorium, the individual is able to describe the

*Correspondence: javedsiddiqui2000@gmail.com

Javed Ather Siddiqui, Department of Psychiatry, Mental Health Hospital,

Taif, Saudi Arabia, P.O.BOX.2056, Taif -21944 (KSA)

Mobile: 00966502752547

Sleep and Hypnosis

Journal homepage:

www.sleepandhypnosis.org

ISSN:1302-1192 (Print) 2458-9101 (Online) experience vividly. The muscle power returns to normal either spontaneously or if the individual is touched by another person. Anxiety may then supervene. Occurrence of $\mathrm{SP}$ in some families raises the possibility of a genetic mechanism (Dahlitz \& Parkes, 1993). Cholinergic drugs (e.g. physostigmine and arecoline) and antihypertensive agents such as prazosin and reserpine precipitate or exacerbate cataplexy (Hishikawa \& Shimizu, 1995) and perhaps SP.

The term "sleep paralysis" was coined by Wilson (1928). SP is considered a disease when recurrent and disturbing, according to the International Classification of Sleep Disorder-3 $3^{\text {rd }}$ edition (ICSD-3) (American Academy of Sleep Medicine [AASM], 2014). SP is classified as a parasomnia and characterized by unusual behavior or abnormal physiological events that occur during the transition between sleep and wakefulness. SP episodes are generally accompanied by intense anxiety, inability to perform voluntary movements (even to scream or cry out for help), and, in some cases, fear of impending death 
(Sharpless et al., 2010; Jalal and Hinton, 2013). SP occurs most commonly in women (Pires et al., 2007; Sharpless and Barber, 2011) and when the body is in supine position (Chilcott et al., 1998; Sharpless etal., 2010). The prevalence of SP among the general population is controversial, ranging from 5 to 62\% (Dahlitz \& Parkes, 1993). In a sample of nearly two thousand Canadian university students, Spanos et al. (1995) found that 21\% of these subjects experienced SP; however, in this sample there was no significant inter-gender difference. Sharpless \& Barber (2011) observed that the prevalence rate of at least one episode of SP in lifetime for the general population, student samples, and psychiatric patients was $7.6,28.3$, and $31.9 \%$, respectively.

Sleep paralysis is associated with either hypnagogic hallucinations (that occur at the onset of sleep) or hypnopompic ones (when waking up) (Dahlitz \& Parkes, 1993). Cheyne et al. (1999) grouped the hallucinations associated with SP into three types: (a) "Intruder"; (b) "Unusual Bodily Experiences"; (c) "Incubus." The "Intruder" type is characterized by a feeling of fear or an unpleasant presence, accompanied by auditory and visual hallucinations. The "Unusual Bodily Experiences" involve hovering sensations and out-of-body experiences, in which individuals see the own body from an external perspective, and interpret as if they have left their physical body (Blackmore \& Parker, 2002; Blanke et al., 2004; de Sá \& Mota-Rolim, 2015). The "Incubus" type refers to feelings of chest pressure and shortness of breath. Cheyne et al. (1999) observed a correlation between types (a) and (c). Cheyne \& Girard (2009) consider that out-of-body experiences and SP hallucinations have different neurobiological basis. Dahlitz \& Parkes (1993) speculate that a lack of synchrony between changes in brain activity and muscle atonia is the mechanism responsible for bodily immobilization during SP.

Most researchers (Hufford DJ, 2005) believe that SP is associated with rapid eye movement sleep (REMS). The relatively high prevalence of depression in individuals with SP (Mariana SC et al., 2007) has led some to suggest that it is an atypical symptom of depression or that it has a shared causal pathway with depression, a suggestion supported by studies showing that antidepressants can relieve the symptoms of SP in some, but not all, patients with SP (Stores G, 2003). In general terms, during SP the brain falls back to an activity pattern similar to when individuals are awake; however, their muscles remain in the typical REMS atony, thus subjects feel as though they have awakened, and yet are unable to move (Dauvilliers et al., 2007; Nishino, 2007; Mahowaldetal., 2011). According to Hufford (2005), until recently SP was constantly underdiagnosed as a narcolepsy symptom. Narcolepsy is a disorder characterized by abnormalities in sleep regulation, including abrupt and involuntary sleep attacks associated with cataplexy (sudden loss of muscle tone), which usually follows a strong burst of emotion. Although it may be associated with Narcolepsy, SP can occur separately: the so-called isolated SP (American Academy of Sleep Medicine [AASM], 2014).

A modern day retelling of SP would correspond to the so-called "alien abductions" (Shermer, 2011). Mack (1997) defines these cases as narratives (conscious or aided by hypnosis) describing the abduction by aliens, which are recorded in the absence of altered mental states - such as those induced by psychotropic substances.

\section{CASE REPORT}

A 35-years old, well body builds male, a private car driver, socially active patient with no prior history of psychiatric illness. The have been referred by his family physician for psychiatric evaluation. He initially complaining of sleep disturbances, and nightmare. This incidence occurs after he used to drive for long distance. He subsequently developed episode of sleep paralysis that is recurrent, he said he is unable to move his body or could not speak and later became panic and were often fearful. This episode of SP occurred randomly either at sleep onset, or upon awakening in the morning. This event lasted for 10-20 minutes, also said that some alien forces like jinn seated over his chest and he is unable to get rid from this frightening situation. These were not associated with vivid dreams. He had experienced similar symptoms of SP more whenever he used to drive for long distances or rare occasions in the remote past, but 
reported worsening in the fervency recently.

On further enquiring on the details of sleep history, he noted symptoms of multiple nightmare awakening, sleep disturbances, day time fatigue. He also reported his irregular sleep schedule as his profession as a driver. He denied symptoms of cataplexy, hallucinations or automatic behaviors. There was no family history of narcolepsy or similar symptoms of SP, no history of alcohol use or other illicit drug use. Laboratory findings including complete blood cell count, serum electrolytes, liver and renal function test, thyroid function test, vitamin B12 and D were within normal limits. He was considered that there was good evidence to support a diagnosis of sleep paralysis with mild depression as he has many family problems so he always preoccupied in thought and sad.

We counseled patient on his sleep hygiene, to get good night's sleep - at least 6-8 hours of sleep at night, go to bed at roughly the same time each night and get up at same time at morning, to create sleep environment that's comfortable, avoids eating big meal, smoking or drinking alcohol or caffeine shortly before going to bed, to do regular exercises. After improving good night's sleep we started antidepressant (serotonin specific reuptake inhibitors) like fluoxetine $20 \mathrm{mg}$ once a day. Patient thinks that SP is result of cultural and spiritual attack that 'alien abductions' or jinn seated over his chest, so we referred this patient to our psychologist and social workers for counseling and cognitive behavior therapy. After 3 weeks patient attended in our out-patient department and we found that his sleep was improved and has no episode of sleep paralysis.

\section{DISCUSSION}

Sleep paralysis is characterized by body immobility, chest pressure, seeing scary figures, and/or feeling a frightening "presence," which tends to happen during awakening in supine position. SP is thought by some to account for not only many alien abduction delusions, but also ghost sightings and delusions involving paranormal or supernormal experiences. The common theme in all these explanations is a nocturnal visitation of demons and devils or jinn. As described along this article, the interpretation of SP rebirths in different eras and cultures, such as the Saudi Arabian culture its Al-jathoum, Greek"ephialtes" the nocturna oppression of Ancient Roman, Fuseli's "The nightmare," the Japanese kanashibari, the Egyptian Jinn, and the modern "alien abductions," among others and in Brazil is usually described as Pisadeira attacks (Corso, 2002; Pires,2002; Cascudo, 2012). Cascudo (2012) investigates Pisadeira etymology and relates it to the Portuguese word "pesadelo" (nightmare), akin to its original meaning, the Spanish pesadilla ("heavy" or "weighed"). The patient experienced SP since one year, it's episodic. At first presentation our diagnosis is inadequate sleep hygiene due to long driving schedule with insufficient total sleep time, periodic sleep paralysis and mild depression due to his family problems.

Reassurance and explanation of the physiological basis may suffice (Dahlitz \& Parkes, 1993), some patients may need anxiolytic medication (Nardi, 1981) and, recently, fluoxetine (Koran \& Raghavan, 1993) have been tried with success. Tricyclic antidepressants, monoamine oxidase inhibitors, yohimbine, and anticholinergics have also been reported to be effective in abolishing SP (Hishikawa \& Shimizu, 1995). We counseled our patient to improve his sleep hygiene, after improved sleep we started anti-depressant like citalopram to regulate sleep cycle, and to get rid from family stressors. It is possible that the escalating stress is due to his depression with sleep disturbances, and for long drive has been precipitated SP. The role of long day and night drive and family stresses is also the causation of sleep paralysis. We referred patient to our psychologist and social worker for removing cultural and spiritual attack of 'alien abductions' like 'jinn' that seated over their chest. They received counseling and cognitive behavior therapy. 


\section{References}

American Academy of Sleep Medicine [AASM] (2014). International classification of sleep disorders: Diagnostic and coding manual. Darien, CT: American Academy of Sleep Medicine.

Blackmore, S. J., and Parker, J. D. (2002). Comparing the content of sleep paralysis and dream reports. Dreaming, 12, 45-59.

Blanke, O., Landis, T., Spinelli, L., and Seeck, M. (2004). Out-ofbody experience and autoscopy of neurological origin. Brain, 127, 243-258.

Spanos, N. P., McNulty, S. A., DuBreuil, S. C., Pires, M., \& Burgess, M. F. (1995). The frequency and correlates of sleep paralysis in a university sample. Journal of Research in Personality, 29(3), 285305.

Cascudo, L. C. (2012). Dicionáriodo Folclore Brasileiro. São Paulo: Global.

Cheyne, J. A., \& Girard, T. A. (2009). The body unbound: Vestibular-motor hallucinations and out-of-body experiences. Cortex, 45(2), 201-215.

Cheyne, J. A., Rueffer, S. D., \& Newby-Clark, I. R. (1999). Hypnagogic and hypnopompic hallucinations during sleep paralysis: neurological and cultural construction of the nightmare. Consciousness and Cognition, 8(3), 319-337.

Corso, M. (2002). Monstruário: Inventário de Entidades Imaginárias e de Mitos Brasileiros. Porto Alegre: TomoEditorial.

Dahlitz, M., and Parkes, J. D. (1993). Sleep paralysis. Lancet, 341, 406-407.

Dauvilliers, Y., Arnulf, I., and Mignot, E.(2007). Narcolepsy with cataplexy. Lancet, 369,499-511.

De Sá, J. F. R., \& Mota-Rolim, S. A. (2015). Experiências fora do corpo: aspectos históricos e neurocientíficos. Ciências \& Cognição, 20(1) 189-198.

Hinton, D. E., Hufford, D. J., \& Kirmayer, L. J. (2005). Culture and sleep paralysis. Transcultural Psychiatry, 42, 5-10.

Hishikawa, Y., \& Shimizu, T. (1994). Physiology of REM sleep, cataplexy, and sleep paralysis. Advances in Neurology, 67, 245271.
Hufford, D. J. (2005). Sleep paralysis as spiritual experience. Transcultural Psychiatry, 42, 11-45.

Jalal, B., \& Hinton, D. E. (2013). Rates and characteristics of sleep paralysis in the general population of Denmark and Egypt. Culture, Medicine, and Psychiatry, 37(3), 534-548.

Koran, L. M., \& Raghavan, S. (1993). Fluoxetine for isolated sleep paralysis. Psychosomatics, 34(2), 184-187.

Mack, J. E. (1997). Abduções. RiodeJaneiro: EDUCARE.

Mahowald, M. W., Cramer Bornemann, M. A., and Schenck, C. H. S. (2011). State dissociation, human behavior, and consciousness. Current Topics in Medicinal Chemistry, 11(19), 2392-2402.

Mariana, S. C., Teppy, Y., Laurel, F., and Emmanuel, M. (2007). Depression: relationships to sleep paralysis and other sleep disturbances in a community sample. Journal of Sleep Research, 16(3), 297-312.

Nardi, T. J. (1981). Treating sleep paralysis with hypnosis International Journal of Clinical and Experimental Hypnosis, 29(4), 358-365.

Nishino, S. (2007). Clinical and neurobiological aspects of narcolepsy. Sleep Medicine, 8(4), 373-399.

Pires, C. (2002). Conversas ao pé-do-fogo: Estudinhos Costumes - Contos Anedotas-CenasdeEscravidão.Itu:Ottoni.

Sharpless, B. A., \& Barber, J. P. (2011). Lifetime prevalence rates of sleep paralysis: a systematic review. Sleep Medicine Reviews, 15(5), 311-315.

Sharpless, B. A., McCarthy, K. S., Chambless, D. L., Milrod, B. L., Khalsa, S. R., \& Barber, J. P. (2010). Isolated sleep paralysis and fearful isolated sleep paralysis in outpatients with panic attacks. Journal of Clinical Psychology, 66(12), 1292-1306.

Shermer, M. (2011). Por Que as Pessoas Acreditam em Coisas Estranhas: Pseudociência, Superstição e Outras Confusões dos Nossos Tempos. São Paulo: JSNEditora

Stores, G. (2003). Medication for sleep-wake disorders. Archives of Disease in Childhood, 88(10), 899-903.

Wilson, S. A. K. (1928). The narcolepsies. Brain: A Journal of Neurology, 51, 63-109. 